\title{
A Method for Measurement of Arterial Concentration of Cerebral Blood Flow Tracer for Autoradiographic Experiments
}

\author{
Devidas Menon, Mirko Diksic, Ernst Meyer, Kazuhiro Sako, and Y. Lucas Yamamoto
}

\begin{abstract}
A new method for continuous monitoring of the concentration of ${ }^{131}$ I-labelled iodoantipyrine during an autoradiographic local cerebral blood flow (LCBF) experiment is described. During infusion of iodoantipyrine, radioactivity in an external femoral arteriovenous loop is monitored by a scintillation detector. Data is collected with a variable time base, and the arterial activity curve displayed visually in its entirety. The main advantage of this method is that there is no blood loss. It will therefore be of particular importance in dual-label autoradiography. This method can also be used for other gamma-emitting blood flow tracers, e.g. ${ }^{123}$ I-iodoantipyrine.
\end{abstract}

RÉSUMÉ: On décrit une nouvelle méthode de contrôle continu de la concentration d'iodoandtipyrine marquée à l'iode-131 durant une expérience de débit sanguin cérébral régional par méthode autoradiographique. Durantl'infusion d'iodoantipyrine, la radioactivité dans une anse artérioveineuse fémorale externe a été surveillée à l'aide d'un détecteur à scintillation. Les données sont recueuillies selon un point de départ variable et la courbe intégrale d'activité artérielle est déployée visuellement. L'avantage majeur de cette méthode est qu'il n'y a pas de perte de sang. Ceci sera donc d'une importance particulière dans l'autoradiographie à doublemarqueur. Cette méthode peut aussi être utilisée avec d'autres substances émettant des rayons gamma, tel l'iodoantipyrine marquée à l'iode-123.

Can. J. Neurol. Sci. 1984; 11:380-382

Conventional local cerebral blood flow (LCBF) and local cerebral glucose utilization (LCGU) measurements by means of autoradiography use ${ }^{14} \mathrm{C}$-labelled iodoantipyrine $\left({ }^{14} \mathrm{C}\right.$-IAP) (Sakurada et al, 1978) and ${ }^{14} \mathrm{C}$-labelled deoxyglucose $\left({ }^{14} \mathrm{C}-\mathrm{DG}\right)$ (Sokoloff et al, 1977). However, because of the destructive nature of autoradiography, it is impossible to measure both blood flow and glucose utilization in the same animal using the same radioisotope label. Consequently, dual-label autoradiographic techniques using ${ }^{14} \mathrm{C}$-DG in conjunction with either ${ }^{131}$ I-IAP or ${ }^{123}$ I-IAP(Lear et al., 1981; Mies et al., 1981; Blasberg et al., 1980) have recently been devised. By taking advantage of the different half-lives and decay modes, or by using a filter, it is possible to determine the concentrations of the two tracers on an autoradiogram as well as in arterial blood samples.

Calculation of LCBF and LCGU requires a good estimate of the arterial tracer concentration, and this necessitates collection of a fairly large number of blood samples. Blood loss can be substantial: in some cases, 3 to $4 \mathrm{ml}$ of blood is drawn for LCBF and $2 \mathrm{ml}$ for LCGU. For a small animal such as a rat, this can amount to $25 \%$ of total blood volume. Consideration of this, and of the resulting physiological changes, prompted us to investigate a new way of determining the arterial activity curve during an LCBF measurement.

\section{METHODS}

In our standard technique for autoradiographic measurement of LCBF with ${ }^{14} \mathrm{C}$-labelled iodoantipyrine, freely flowing blood from a femoral arterial catheter was dropped onto recording paper moving at a fixed rate $(2.5 \mathrm{~cm} / \mathrm{sec})$. Since the rate of movement was known, the time of the drops could be determined by measuring the distance from the starting point. Twenty microliters were micropipetted from up to 24 of these drops, added to a liquid scintillation solution, and assayed for ${ }^{14} \mathrm{C}$. The technique required femoral venous catheterization for infusion of IAP and femoral arterial catheterization for blood sampling.

The new method we propose uses ${ }^{131}$ I-labelled IAP for LCBF determination. Although the resolution of autoradiographs with ${ }^{131} \mathrm{I}$ is not as high as with ${ }^{14} \mathrm{C}$, use of ${ }^{131} \mathrm{I}$ allows dual-tracer experiments to be performed. 
In this new method, both femoral veins and one femoral artery are catheterized. The tracer is injected into one vein; the other vein and artery are connected by PE-20 tubing formed into an external arteriovenous loop. The loop is made as short as possible, about $15 \mathrm{~cm}$. Activity in the blood can be measured directly as it flows through this loop. Five centimeters of lead shield the detection system from the animal and the infusion pump which contains the IAP. The loop passes through this lead shield onto the face of a well collimated, $\phi=3.81 \mathrm{~cm}$ $\mathrm{NaI}(\mathrm{Tl})$ crystal, which is shielded with 1.27 -cm-thick lead sheeting pierced by a $2 \mathrm{~mm}$ hole. The counts registered by the detector therefore originate in this $2 \mathrm{~mm}$ segment of the loop. The detector is connected to a 1024 channel analyser with a low energy discriminator setting of $150 \mathrm{keV}$.

The $1.27 \mathrm{~cm}$ of lead will allow less than $4 \%$ of the ${ }^{131}$ I emissions from the blood to penetrate to the crystal face. At the same time, the shielding around the animal and the pump effectively protects them from radiation. The shielding was tested by removing the loop from the detector face immediately after the infusion was completed; count rates then dropped to background levels.

The experimental procedure stipulates the infusion of ${ }^{131}$ I-IAP for one minute at a pre-programmed rate. The aquisition time for the scintillation detector is 2 or 3 seconds. At the end of the infusion, the animal is decapitated and prepared for autoradiography. The loop count rates, which are stored in the multichannel analyser, are then read back and recorded on the experimental sheet. The entire arterial curve can also be displayed on the analyser, so that the shape of the arterial input can be seen immediately after the experiment.

This method has been evaluated by comparison with the existing sampling method. The rats used were catheterized bilaterally in the femoral veins and arteries. A continuous infusion of 200 to $400 \mu \mathrm{Ci}$ of ${ }^{131} \mathrm{I}$-IAP was made in accordance with the LCBF protocol. During this time, arterial blood was sampled from the femoral artery on the infusion side, using the micropipetting technique described earlier. Simultaneously, the activity in the arteriovenous loop on the other side was monitored using the detection system. After the loop activity was recorded, the collected blood samples were counted in a well-counter calibrated for ${ }^{131} I$.

Our new technique for actual calculation of LCBF calls for specific activity in the blood, not just count rates, and hence calibration of the system. The system was calibrated by injecting with a peristaltic pump various known concentrations of ${ }^{131}$ I-IAP into catheter tubing of exactly the same length as the one used on the rats. For each concentration, the pump was run at a number of different flow rates, ranging from 0.5 to $3.8 \mathrm{ml} / \mathrm{min}$. The corresponding count rates as determined by the detector were then recorded.

\section{Results AND Discussion}

Sampling of arterial blood by conventional means during an IAP experiment, or during a DG experiment for that matter, entails considerable blood loss. In IAP experiments, because of the volume of infusate and blood loss, there are consistent reductions in hematocrit through the course of the experiment. In a series of seven IAP experiments conducted to quantitate the effect of blood loss on hematologized parameters, measure- ments of hematocrit before and after the experiment showed a mean reduction of $10 \%$ (ranging from $44.1 \% \pm 5.67 \%$ to $39.7 \pm$ 6.02). The largest reduction was $17 \%$. Blood loss of this order could have serious effects on the hemodynamics. We have also found reductions in arterial blood pressure, presumably also related to blood volume reduction. In addition, in some of the techniques employed for blood sampling the concentration, of tracer per unit weight is determined from the weight of the sample. From this, the concentration per unit volume is obtained by assuming a value for the specific gravity of blood. This, in turn, is related to hematocrit, which falls during the experiment. It was consideration of these factors that led us to devise a method requiring minimal blood loss.

Our validation experiments, Figure 1, show that the arteriovenous loop activity is representative of the activity as measured by conventional means. The well-counter measurements of the individual drops of blood are represented by solid circles, and the loop count rates appear in open circles. The two sets of data have been normalized by taking ratios of the two count rates at those points in time when an actual blood sample was drawn, and then averaging these ratios. This average was then used as a normalization factor to display the data on the same scale.

In addition, we found that the loop activity is independent of flow rate for a fairly wide range of loop flow rates. Cerebral blood flow rates corresponding to the range of loop flow rates as generated by the peristaltic pump covered a wide range, including the types of values that one would commonly encounter in rat experiments.

\section{Concentrations of ${ }^{131}$ I-IAP in Arterial Blood Samples and in Arteriovenous Loop}

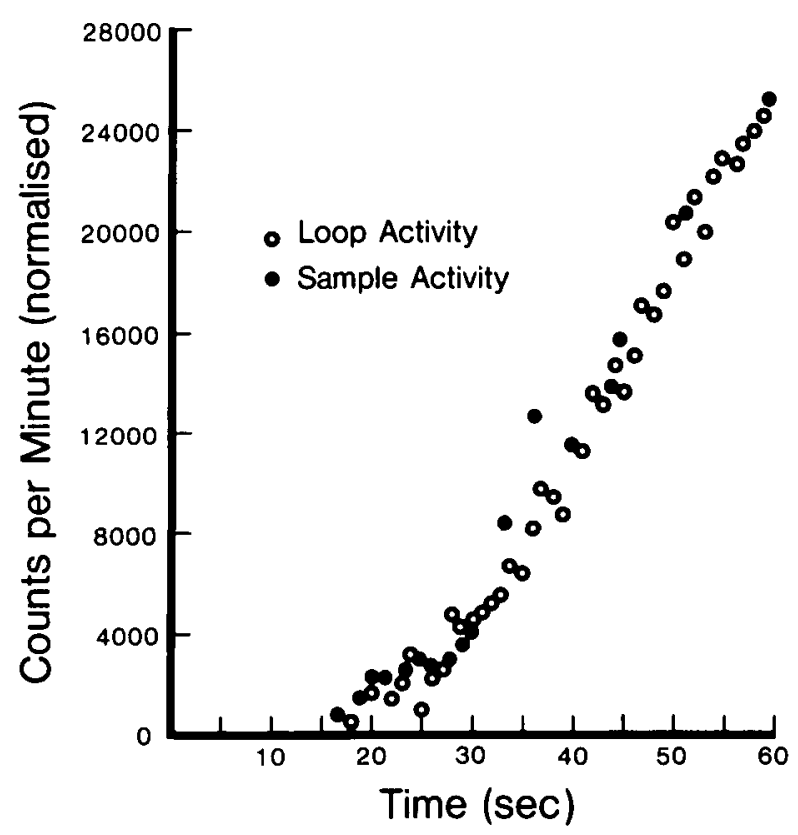

Figure 1 - Correlation of radioactivity in arterial blood and in the arteriovenous loop as a function of time. The vertical bar through each of the 5 data points represents the standard deviation based on measurements at 9 flow rates at each concentration. 
The calibration graph is shown in Figure 2. Each of the five data points corresponds to one concentration of ${ }^{131} \mathrm{I}$-IAP. In determining these values, the mean and standard deviation for nine different flow rates at each concentration were calculated. The vertical bars on the data points represent the standard deviations. The relationship between count rate and specific activity is linear. The intercept of the calibration line $(0.25)$ is negligible for count rates over $1000 \mathrm{cpm}$, and so the ${ }^{131} \mathrm{I}-\mathrm{IAP}$ concentration can be determined by merely multiplying the measured count rate per minute by the slope of the line, which is 0.00945 .

There are two other advantages to this system. First, once the system has been set up and calibrated, it is far easier to use than conventional methods, where a technician must obtain 20-30 samples of blood in a very short time. Second, the full arterial activity curve can be displayed immediately after the experiment. This would allow the experiment to be discontinued should the arterial data be found unacceptable. Decapitation of the animal, and freezing and sectioning of the brain, which require time and effort, can be avoided in such cases. Also, problems with the arterial activity curve, which in turn result from problems with the infusion schedule, are not infrequent. With this system they can be detected immediately.

The catheter should be as short as possible. An excessively long catheter will affect the hemodynamics, as well as causing a smearing effect on the measured activity (Reivich et al., 1969). In any case, the length of the entire loop has to be the same for both the calibration and the actual experiment.

At the moment this loop technique is feasible only for gammaemitters such as ${ }^{131}$ I. However, the plastic scintillation detectors that have recently become available could make this loop technique feasible with beta-emitting isotopes as well.

\section{Calibration Graph for the A-V Loop Detection System}

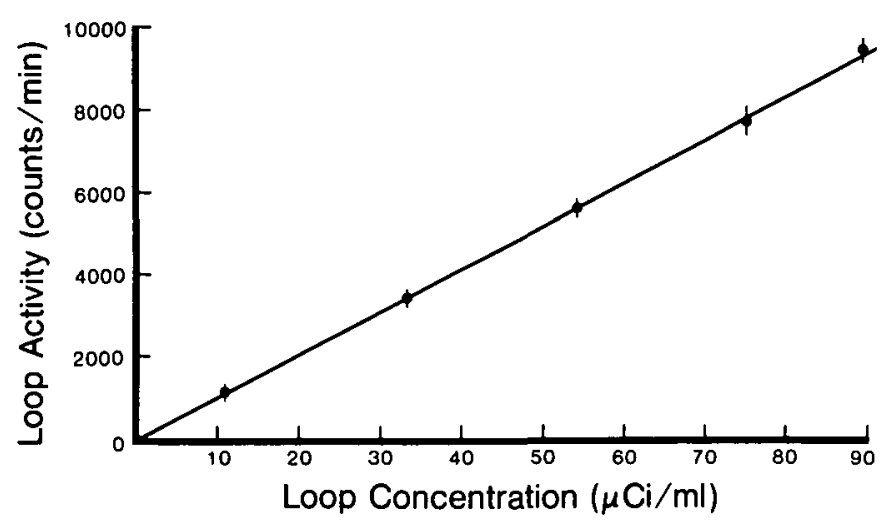

Figure 2 - Calibration line for the arteriovenous loop.
Because of recent interest in dual-label and even triple-label autoradiography (Mies et al., 1983), IAP labelled with ${ }^{123} \mathrm{I},{ }^{131} \mathrm{I}$, and positron emitting radioisotopes is being used more often (Sako et al., 1983). In such experiments, where blood loss would be even more drastic using the older techniques, the system described here could be especially valuable.

Furlow et al. (1983) described a double-tracer method that involves washing out one tracer $\left({ }^{14} \mathrm{C}\right.$-IAP), thereby permitting measurement of two variables in the same animal. In a recent paper (Sako et al., submitted) we discuss the limitations of this method.

\section{ACKNOWLEDGEMENTS}

This work was supported by the Medical Research Council of Canada (PET-Program Grant No. Sp. 5 and Grant No. MA-3174), the Alberta Heritage Foundation for Medical Research (D. Menon), the Cone Memorial Research Fund and Clive Baxter Research Fund of the Montreal Neurological Institute, and a Killam Scholarship (to M. Diksic and E. Meyer). Our thanks are extended to Dr. Victoria Lees for editing this manuscript.

\section{REFERENCES}

Blasberg RG, Gazendam J, Patlak CS, Fenstermacher JD (1980) Quantitative autoradiographic studies of brain edema and a comparison of multi-isotope autoradiographic techniques. Adv. Neurol. 28: 255-270.

Furlow TW, Martin RM, Harrison LE (1983) Simultaneous measurement of local glucose utilization and blood flow in the rat brain: An autoradiographic method using two tracers labelled with carbon-14. J. Cereb. Blood Flow Metabol. 3: 62-66.

Lear JL, Jones SC, Greenberg JH, Fedora TJ, Reivich M (1981) Use of ${ }^{123} \mathrm{I}$ and ${ }^{14} \mathrm{C}$ in a double radionuclide autoradiographic technique for simultaneous measurement of LCBF and LCMRGI. Stroke 12: 589-597.

Mies G, Bodsch W, Hossmann K-A (1983) Experimental application of triple-labeled quantitative autoradiography for measurement of cerebral blood flow, glucose metabolism, and protein synthesis. In "Positron Emission Tomography of the Brain", Edited by Heiss, W.-D. and Phelps, M.E. , Springer-Verlag, N.Y., 1983, pp. $19-29$.

Mies G, Niebuhr I, Hossmann K-A (1981) Simultaneous measurement of blood flow and glucose metabolism by autoradiographic techniques. Stroke 12: 581.588.

Reivich M, Jehle J, Sokoloff L, Kety SS (1969) Measurement of regional cerebral blood flow with antipyrine- ${ }^{14} \mathrm{C}$ in awake cats. J. Appl. Physiol. 27: 296-300.

Sako K, Diksic M, Kato A, Menon D, Yamamoto YL, Feindel W (1983) Evaluation of ${ }^{18} \mathrm{~F}$-4-fluoroantipyrine as a tracer for quantitative measurement of LCBF. J. Cereb. Blood Flow Metab. 3: S99-S100.

Sakurada O, Kennedy C, Jehle J, Brown JD, Carbin GL, Sokoloff L (1978) Measurement of local cerebral blood flow with iodo $\left({ }^{14} \mathrm{C}\right)$ antipyrine. Am. J. Physiol. 234: H59-H66.

Sokoloff L, Reivich M, Kennedy C, Des Rosiers MH, Patlak CS, Pettirew KD, Sakurada O, Shinohara M (1977) The ${ }^{14} \mathrm{C}$ deoxyglucose method for the measurement of local cerebral glucose utilization: theory, procedure and normal values in the conscious and anesthetized albino rat. J. Neurochem. 28: 897-916. 